\title{
Recurrent Endometrial Adenocarcinoma
}

National Cancer Institute

\section{Source}

National Cancer Institute. Recurrent Endometrial Adenocarcinoma. NCI Thesaurus. Code C158437.

The reemergence of endometrial adenocarcinoma after a period of remission. 